\title{
How to adjust drug doses in chronic kidney disease
}

\section{SUMMARY}

Drugs excreted by the kidney require dose reduction in chronic kidney disease. This adjustment depends on the severity of the disease and what proportion of the drug is eliminated by the kidneys.

The estimated glomerular filtration rate can generally be used to guide dose adjustment in patients with stable kidney function. However, the formula can be misleading in some patient subsets and other approaches are required.

At extremes of body mass, the estimated glomerular filtration rate can under- or overestimate kidney function. It may need to be adjusted for body surface area, particularly for drugs with a narrow therapeutic range or requiring a minimum concentration to be effective. Close monitoring of drug effect and toxicity is also needed and can be supported by therapeutic drug monitoring.

For short courses of drugs with a wide therapeutic index, dose adjustment may not be needed.

Alternative methods for quantifying kidney function include the Cockcroft-Gault formula (estimates creatinine clearance) or direct measures of glomerular filtration rate using exogenous isotope compounds. These are not commonly required.

\section{Introduction}

Chronic kidney disease is defined by a glomerular filtration rate (GFR) of less than $60 \mathrm{~mL} / \mathrm{min} / 1.73 \mathrm{~m}^{2}$ or evidence of glomerular-tubular injury, for example haematuria or proteinuria. The diagnosis is becoming more common with $1.0 \%$ of Australians being diagnosed in 2017-18. In those over 75 years old, the prevalence was 4.6\%. However, biochemical results indicate the actual prevalence may be closer to $10 \%$ in adults, ${ }^{2}$ and more than $30 \%$ in a hospital population. ${ }^{3}$

Many drugs are eliminated by the kidney to some extent. If the dosage is not appropriately decreased in a patient with chronic kidney disease, drug concentrations can increase, risking adverse drug reactions. On the other hand, unnecessary decreases in dosage may result in undertreatment, or changing to an alternate drug with a narrower therapeutic index, lower efficacy or both. Examples include changing a patient with chronic kidney disease from metformin to a sulfonylurea (lower effectiveness and reduced long-term benefit), or rivaroxaban to warfarin (narrower therapeutic index and requiring more blood tests).

The requirement for dose adjustments in adults with chronic kidney disease should be anticipated at the point of prescribing. It is important for prescribers to understand that there are different methods of calculating the dose adjustments in these patients.

\section{The influence of kidney disease on drug prescribing}

The need for and extent of dose adjustment depends on the severity of chronic kidney disease, the proportion of the drug eliminated by the kidney, the risk of adverse effects from the drug, the duration of treatment and if the drug has active or toxic metabolites that rely on the kidney for elimination. ${ }^{4}$ Drug toxicity due to an inappropriately high dosage is seen after multiple doses due to drug accumulation, rather than after the first dose. ${ }^{5}$ The dose adjustment in patients with kidney disease involves increasing the dosing interval or reducing the dose.

\section{Quantifying kidney function}

GFR is the key clinical measure of kidney function. In general, for drugs that are excreted by the kidney, a decrease in GFR is associated with a decrease in drug clearance and the dosage needs to be reduced.

The GFR can be quantitated in multiple ways and each has advantages and disadvantages. The measured GFR (mGFR) is the gold standard but it is resource intensive and expensive, so the estimated GFR (eGFR) is used to classify and monitor the severity of chronic kidney disease (Table 1).

\section{Serum creatinine-based formulae}

GFR can be assessed using serum creatinine-based formulae - Cockcroft-Gault ${ }^{6}$ and CKD-EPI (Chronic Kidney Disease Epidemiology Collaboration) ${ }^{7}$. Since

\section{Maurizio Stefani \\ Advanced traineel, \\ Richard F Singer \\ Staff specialist ${ }^{3}$ \\ Darren M Roberts \\ Staff specialist ${ }^{1,3,4}$ \\ Conjoint associate professor $^{2}$}

' Department of Clinical Pharmacology and Toxicology, St Vincent's Hospital, Sydney

${ }^{2}$ St Vincent's Clinical School, University of New South Wales, Sydney

${ }^{3}$ Department of Renal Medicine, Canberra Hospital and Community Services, Canberra

${ }^{4}$ Department of Renal Medicine and Transplantation, St Vincent's Hospital, Sydney

\section{Keywords}

chronic renal insufficiency, creatinine, drug dosage calculations, glomerular filtration rate

Aust Prescr 2019:42:163-7 https://doi.org/10.18773/ austprescr.2019.054 
creatinine is an end product of muscle breakdown, each formula allows for the serum creatinine concentration to be adjusted for body mass based on patient characteristics.

The Cockcroft-Gault formula estimates creatinine clearance $(\mathrm{eCrCl})$ and incorporates age, sex and body weight (Box 1). ${ }^{6}$ Because $\mathrm{eCrCl}$ was validated against measured $\mathrm{CrCl}$ based on 24-hour urine collection, it overestimates the actual GFR given that creatinine is both filtered and secreted in the nephron tubules. The usual units for $\mathrm{eCrCl}$ are $\mathrm{mL} /$ minute and multiple online calculators are available. However, by 2010 most laboratories in Australia were using a newer creatinine assay standardised to isotope dilution mass spectrometry (IDMS) which resulted in a $10-20 \%$ decrease in creatinine concentrations. This, in turn, will increase the $\mathrm{eCrCl}$ compared to what would have been calculated pre-2010.

The CKD-EPI formula estimates GFR because it was validated against GFR measured using exogenous

\section{Table 1 Relationship between glomerular filtration rate and stage of chronic kidney disease*}

\begin{tabular}{ll}
\hline Kidney function stage & eGFR $\left(\mathbf{m L} / \mathbf{m i n} / \mathbf{1 . 7 3} \mathbf{~ m}^{\mathbf{2}}\right)$ \\
\hline 1 & $\geq 90$ \\
\hline 2 & $60-89$ \\
\hline $3 a$ & $45-59$ \\
\hline $3 b$ & $30-44$ \\
\hline 4 & $15-29$ \\
\hline 5 & $<15$ or on dialysis \\
\hline
\end{tabular}

eGFR estimated glomerular filtration rate

* The stage of chronic kidney disease is not only based on eGFR, but also on an assessment of kidney damage (eg. proteinuria, haematuria)

\section{Box 1 Formulae used in estimating glomerular filtration rates}

Cockcroft-Gault creatinine clearance $(\mathrm{mL} / \mathrm{min})$

$=(140-$ age $) \times$ weight $\div$ serum creatinine $\times 0.814$ ( $\times 0.85$ if female $)$

De-indexed eGFR (mL/min):

$=\mathrm{eGFR}\left(\mathrm{mL} / \mathrm{min} / 1.73 \mathrm{~m}^{2}\right) \times$ patient's body surface area $\div 1.73$

Body surface area $\left(\mathrm{m}^{2}\right)$ :

$=0.007184 \times$ weight $^{0.425} \times$ height $^{0.725}$

Ideal body weight $(\mathrm{kg})$ :

$=($ height -152.4$) \times 0.9+45.5$ (+ 4.5 if male $)$

Adjusted ideal body weight $(\mathrm{kg})$ :

$=$ IBW $+0.4 \times$ (weight - IBW $)$

Serum creatinine (micromol/L), weight $(\mathrm{kg})$, height $(\mathrm{cm})$, age (years) eGFR estimated glomerular filtration rate

IBW ideal body weight filtration markers. ${ }^{7}$ It incorporates age and sex into a relatively complicated formula. These demographics are known at the time of blood collection so the eGFR is automatically calculated and reported by the laboratory. The units for the automated eGFR are $\mathrm{mL} / \mathrm{min} / 1.73 \mathrm{~m}^{2}$ and it is now an accepted method for the classification and monitoring of chronic kidney disease (Table 1). ${ }^{8,9}$

The initial report describing the CKD-EPI formula did not observe an effect of age or body mass index (BMI) on the accuracy of its prediction. ${ }^{7}$ However, it should be noted that the initial report was based on a population who were mostly younger than 66 years old with a mean body surface area of 1.90-1.93 $\mathrm{m}^{2}$ and a BMI of $27-28 \mathrm{~kg} / \mathrm{m}^{2}$ (mean height $170 \mathrm{~cm}$, mean weight 79-82 kg). The automated eGFR may not therefore apply to patients with different demographics. Since the body surface area for most patients is higher than $1.73 \mathrm{~m}^{2}$, the actual GFR in such a patient will be higher than that reported by the laboratory. The eGFR can be de-indexed (converted to actual $\mathrm{mL} / \mathrm{min}$ ) by multiplying the automated eGFR by the patient's body surface area $\left(\mathrm{m}^{2}\right)$ and then dividing by 1.73 (see Box 1).

\section{Measured GFR}

The mGFR is determined after giving an exogenous filtration marker, such as ${ }^{51} \mathrm{Cr}$-EDTA, ${ }^{125}$ /-iothalamate, DTPA or MAG3. It is the most reliable method of quantifying GFR because these markers are filtered and not substantially secreted into or reabsorbed from the nephron. The mGFR can be indexed by adjusting for a standard body surface area of $1.73 \mathrm{~m}^{2}$. The mGFR methods require parenteral administration of the exogenous marker and multiple blood and sometimes urine samples over time. The incremental gain from the mGFR above eGFR is uncertain in most cases, but they are used in specialist practice before a unilateral nephrectomy when considering the split GFR in each kidney.

\section{Serum cystatin C-based formulae}

Cystatin $\mathrm{C}$ is another endogenous solute that can be used to estimate GFR. However, the test is not universally offered by pathology laboratories in Australia at present.

Cystatin $C$ is less influenced by muscle mass, so it may be advantageous in patients at extremes of body weight or those with cirrhosis. An alternative CKD-EPI formula has been developed to incorporate cystatin C.

\section{How accurate are eGFR and $\mathrm{eCrCl}$ ?}

There is debate about which formula - CockcroftGault or CKD-EPI - is preferred for drug dosing because neither is a perfect representation of the true value of the GFR. 
First, the criteria generally applied in developing these formulae are that the estimated value should be within $30 \%$ of the gold standard value (e.g. mGFR). For an eGFR or eCrCl in any patient at any time, the true GFR or $\mathrm{CrCl}$ could be nearly half or double that of the estimated value (so the absolute variability increases at higher GFRs, see Fig.). This significant uncertainty probably reduces the impact of the IDMS-standardisation of creatinine assays on the calculated eCrCl.

Second, the eCrCl and automated eGFR do not give exactly the same results and $\mathrm{eCrCl}$ generally overestimates mGFR. ${ }^{10}$ For patients with a body surface area that is substantially different from $1.73 \mathrm{~m}^{2}$, the eGFR can be de-indexed to give units of $\mathrm{mL} /$ minute (Box 1). This value is used to inform drug dosing. For example, for the average patient enrolled in the study that developed the CKD-EPI formula, ${ }^{7}$ the mean actual GFR ( $\mathrm{mL} / \mathrm{min})$ is approximately $10 \%$ higher than the automated eGFR, and more than $30 \%$ higher for those who are taller or heavier.

\section{When the automated eGFR is an unreliable estimate of $\mathrm{eCrCl}$ or $\mathrm{mGFR}$}

Some dosing recommendations are based on eCrCl so it is useful to understand how eGFR relates to eCrCl and the gold standard measurement mGFR.

The eGFR and $\mathrm{eCrCl}$ formulae were validated in people older than 18-20 years, and advancing age is associated with imprecision. For example, a study in patients over 60 years of age found that $\mathrm{eCrCl}$ and de-indexed eGFR were within $10 \%$ of each other in only $45 \%$ of cases and in most of these cases the eCrCl was lower than eGFR. ${ }^{11}$ The eCrCl was more likely to be lower in patients with a lower body weight (e.g. less than $60 \mathrm{~kg}$ ) and increased age (e.g. older than 80 years)." Unfortunately, mGFR was not measured in this study to assess the accuracy of the two serum creatinine-based formulae.

A study in 269 people aged 70 years and older noted that the absolute bias by $\mathrm{eCrCl}$ was less than that of de-indexed CKD-EPI (bias $-3.2 \pm 14.2 \mathrm{~mL} / \mathrm{min}$ vs $+7.1 \pm 15.1 \mathrm{~mL} / \mathrm{min}$ ) compared to measured $\mathrm{CrCl} .^{12}$ However, another larger study $(n=805)$ with a similar population except for a slightly higher average BMI found that the mean bias of de-indexed CKD-EPI was $+2.7 \mathrm{~mL} /$ minute compared to $\mathrm{mGFR},{ }^{13}$ supporting the use of CKD-EPI.

In obese patients (BMI above $30 \mathrm{~kg} / \mathrm{m}^{2}$ ), automated eGFR can underestimate GFR, and $\mathrm{eCrCl}$ based on actual body weight will overestimate GFR..$^{10,14,15}$ In these patients, $\mathrm{eCrCl}$ based on adjusted ideal body weight (Box 1) or de-indexed eGFR are more reliable estimates of GFR ${ }^{14,15}$ (see Box 2 for an example). The opposite is true with eGFR for those who

\section{Fig. Correlation of eGFR and eCrCl with mGFR*}

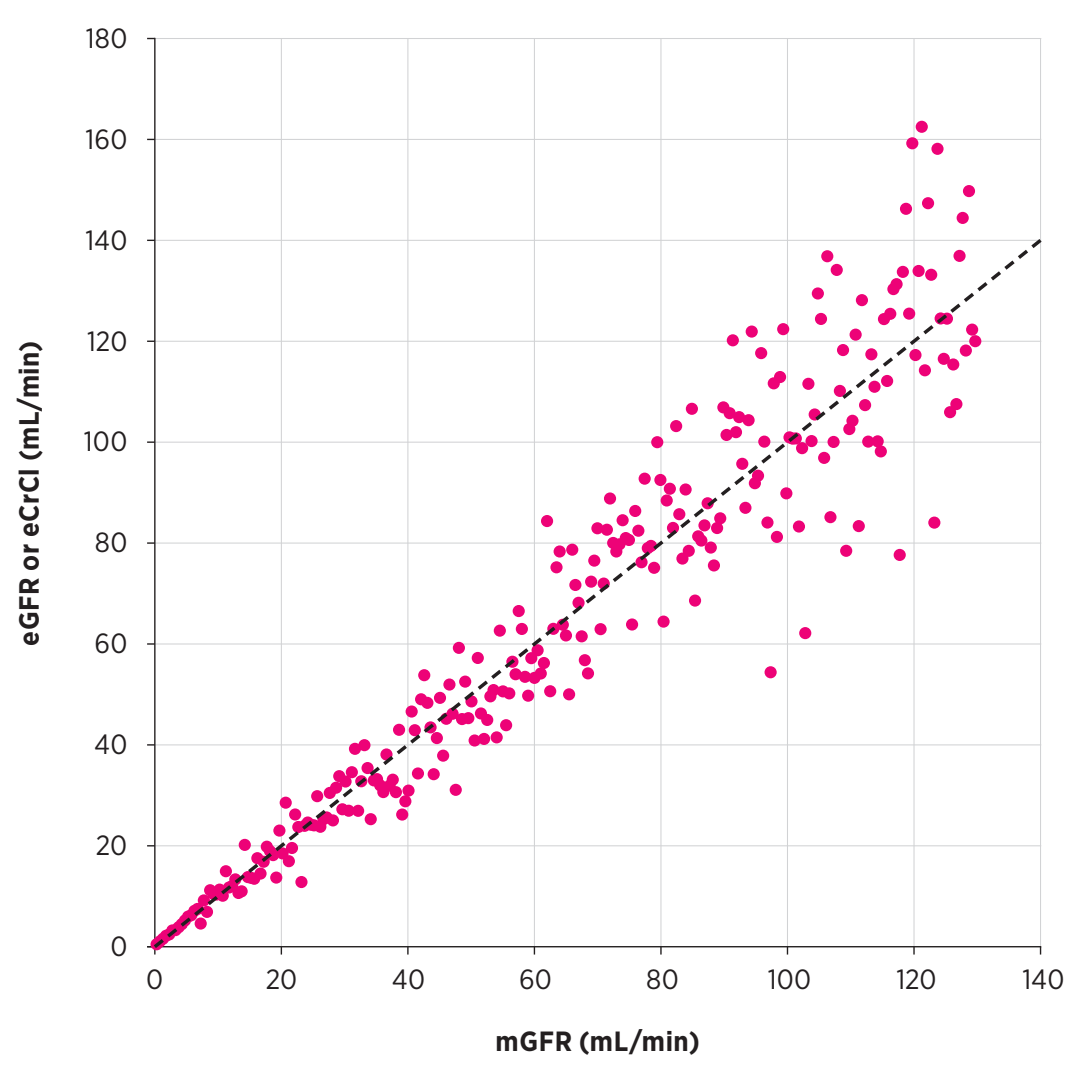

* The correlation of eGFR is imprecise, for example eGFR $30 \mathrm{~mL} / \mathrm{min}$ may reflect an mGFR of $20-40 \mathrm{~mL} / \mathrm{min}$. The error on the prediction of $\mathrm{mGFR}$ from eGFR, and vice versa, increases at higher GFRs. Data based on simulation.

$\mathrm{eCrCl}$ estimated creatinine clearance

eGFR estimated glomerular filtration rate

mGFR measured glomerular filtration rate

are underweight (BMI less than $18.5 \mathrm{~kg} / \mathrm{m}^{2}$ ) with correction for body surface area resulting in a lower GFR estimate. ${ }^{10}$

The accuracy of these formulae may also vary depending on the GFR. For example, automated eGFR may be more accurate than indexed eCrCl at lower GFRs (e.g. less than $30 \mathrm{~mL} / \mathrm{min}$ ) and younger ages (e.g. under 40 years old). ${ }^{10}$

The impact of these patient characteristics on estimates of GFR are summarised in Table 2.

There are many other reasons why drug clearance (renal and non-renal) does not adequately correlate with creatinine-based measures of kidney function. ${ }^{5}$

\section{Dose adjustment based on kidney function}

Despite these complexities and limitations, international and local expert groups support the use of automated eGFR to guide drug dosing. ${ }^{16}$ Overall, this appears reasonable given that potential benefits from a particular method (even if it was 


\section{Box 2 Different methods to assess glomerular filtration rate yield different results}

A 42-year-old man is $1.75 \mathrm{~m}$ tall, weighs $132 \mathrm{~kg}$ (body mass index $43 \mathrm{~kg} / \mathrm{m}^{2}$ and body surface area of $2.5 \mathrm{~m}^{2}$ ) and has a serum creatinine concentration of $300 \mathrm{micromol} / \mathrm{L}$. Glomerular filtration rate indexed to body surface area $1.73 \mathrm{~m}^{2}$ for chronic kidney disease staging:

- automated eGFR $21 \mathrm{~mL} / \mathrm{min} / 1.73 \mathrm{~m}^{2}$

- indexed measured GFR (DTPA) $19 \mathrm{~mL} / \mathrm{min} / 1.73 \mathrm{~m}^{2}$

- indexed measured 24-hour creatinine clearance $36 \mathrm{~mL} / \mathrm{min} / 1.73 \mathrm{~m}^{2}$.

Each of these methods place this man somewhere between Stage 3 and late Stage 4 chronic kidney disease.

Actual glomerular filtration rate for drug dosing:

- de-indexed eGFR $30 \mathrm{~mL} / \mathrm{min}$

- measured GFR (DTPA) $27 \mathrm{~mL} / \mathrm{min}$

- measured 24-hour creatinine clearance $52 \mathrm{~mL} / \mathrm{min}$

- eCrCl (actual body weight) $53 \mathrm{~mL} / \mathrm{min}$

- $\mathrm{eCrCl}$ (ideal body weight) $28 \mathrm{~mL} / \mathrm{min}$

- $\mathrm{eCrCl}$ (adjusted ideal body weight) $38 \mathrm{~mL} / \mathrm{min}$.

Therefore, if a drug's dosage is reduced when a patient's GFR is $<30 \mathrm{~mL} / \mathrm{min}$, the dose for the patient is usually higher if the de-indexed eGFR is used to guide dosing. The preferred formula to guide dosing is not certain at this time, but e $\mathrm{CrCl}$ based on actual body weight and measured 24-hour $\mathrm{CrCl}$ are likely to overestimate the actual GFR.

DTPA diethylenetriaminepentacetate (isotope to measure GFR) eCrCl estimated creatinine clearance (Cockcroft-Gault formula) eGFR estimated glomerular filtration rate (automated)

GFR glomerular filtration rate

Table 2 Impact of patient characteristics on estimates of GFR

\begin{tabular}{|c|c|c|}
\hline Patient characteristic & $\mathrm{eCrCl}$ & eGFR \\
\hline Reduced GFR & May be less accurate & May be more accurate \\
\hline Actual BSA >1.73 m² & $\begin{array}{l}\text { Depends on body } \\
\text { weight only, height is not } \\
\text { incorporated }\end{array}$ & $\begin{array}{l}\text { Actual GFR is }>30 \% \\
\text { higher for taller or } \\
\text { heavier individuals }\end{array}$ \\
\hline Older age (>70 years) & Acceptable & Acceptable \\
\hline Younger age ( $<40$ years) & May be less accurate & May be more accurate \\
\hline $\begin{array}{l}\text { Obesity (e.g. BMI }>30 \mathrm{~kg} / \mathrm{m}^{2} \text { ) } \\
\text { or weight }>120 \mathrm{~kg}\end{array}$ & $\begin{array}{l}\text { Overestimates GFR, use } \\
\text { adjusted ideal body weight }\end{array}$ & $\begin{array}{l}\text { Underestimates GFR, use } \\
\text { de-indexed eGFR }\end{array}$ \\
\hline $\begin{array}{l}\text { BMI }<18.5 \mathrm{~kg} / \mathrm{m}^{2} \text { or weight } \\
<60 \mathrm{~kg}\end{array}$ & $\begin{array}{l}\text { Acceptable, use actual } \\
\text { body weight }\end{array}$ & $\begin{array}{l}\text { Overestimates GFR, use } \\
\text { de-indexed eGFR }\end{array}$ \\
\hline
\end{tabular}

$\mathrm{eCrCl}$ is estimated creatinine clearance as determined by the Cockcroft-Gault formula. The formula was validated against a 24-hour creatinine clearance and the units are $\mathrm{mL} / \mathrm{min}$. Actual body weight is commonly used in the calculations. The $\mathrm{eCrCl}$ is usually higher than the actual GFR.

eGFR is the estimated glomerular filtration rate as determined by the CKD-EPI formula. The formula was validated against a measured glomerular filtration rate and the units are $\mathrm{mL} / \mathrm{min} / 1.73 \mathrm{~m}^{2}$ body surface area.

BSA body surface area

BMI body mass index

GFR glomerular filtration rate used to establish the therapeutic dose) are likely to be reduced in most cases due to inherent errors associated with any of these methods.

Drug information resources do not apply a consistent approach to the dosing of drugs in the context of kidney disease. For example, metformin and rivaroxaban dosing is based on creatinine clearance (presumably Cockcroft-Gault $\mathrm{eCrCl}$ ), eplerenone on eGFR, and tranexamic acid on eGFR or serum creatinine depending on the resource. For lithium or sotalol, guidance for dose reduction is generally vague and a conservative approach is recommended for initial dosing and up-titration.

Small deviations in eGFR are not likely to be clinically meaningful and should not lead to an immediate dose adjustment (or cessation) but instead prompt ongoing monitoring of kidney function.

A more careful approach may be warranted for drugs with a narrow therapeutic index. This is particularly the case if the patient's eGFR is close to a threshold prompting dose adjustment, the patient has a body surface area that differs significantly from $1.73 \mathrm{~m}^{2}$, and the drug requires a minimum concentration to be effective (e.g. antimicrobials). In such cases, the eGFR should be corrected (de-indexed) for the body surface area, and drug efficacy and toxicity should be monitored. Therapeutic drug monitoring is also useful for some medicines such as digoxin, lithium and potentially oral anticoagulants.

\section{Conclusion}

Automated eGFR is an adequate measure of kidney function for drug dosing in most cases, but there are notable exceptions requiring further consideration. Dose adjustment in chronic kidney disease always requires decision making on a case-by-case basis. Alternative laboratory methods for guiding drug dosing are being researched, such as tests based on cystatin C, and may have a useful role in the future. $<$

\section{Darren Roberts is the Chair of the Editorial Executive Committee of Australian Prescriber.}

Acknowledgement: Darren Roberts acknowledges support of the Clinician 'Buy-Out' Program, St Vincent's Centre for Applied Medical Research. 


\section{REFERENCES}

1. Australian Bureau of Statistics. National health survey: first results, 2017-18. ABS Catalogue No. 4364.0.55.001. https://www.abs.gov.au/AUSSTATS/abs@.nsf/ DetailsPage/4364.0.55.0012017-18 [cited 2019 Sep 1]

2. Australian Bureau of Statistics. Australian health survey: biomedical results for chronic diseases, 2011-12. ABS Catalogue No. 4364.0.55.005. https://www.abs.gov.au/ AUSSTATS/abs@.nsf/DetailsPage/4364.0.55.0052011-12 [cited 2019 Sep 1]

3. Ko S, Venkatesan S, Nand K, Levidiotis V, Nelson C, Janus E. International statistical classification of diseases and related health problems coding underestimates the incidence and prevalence of acute kidney injury and chronic kidney disease in general medical patients. Intern Med J 2018:48:310-5. https://doi.org/10.1111/imj.13729

4. Roberts DM, Sevastos J, Carland JE, Stocker SL, Lea-Henry TN Clinical pharmacokinetics in kidney disease: application to rational design of dosing regimens. Clin J Am Soc Nephrol 2018;13:1254-63. https://doi.org/10.2215/CJN.05150418

5. Lea-Henry TN, Carland JE, Stocker SL, Sevastos J, Roberts DM. Clinical pharmacokinetics in kidney disease: fundamental principles. Clin J Am Soc Nephrol 2018:13:1085-95. https://doi.org/10.2215/CJN.00340118

6. Cockcroft DW, Gault MH. Prediction of creatinine clearance from serum creatinine. Nephron 1976;16:31-41. https://doi.org/10.1159/000180580

7. Levey AS, Stevens LA, Schmid CH, Zhang YL, Castro AF 3rd, Feldman HI, et al.; CKD-EPI (Chronic Kidney Disease Epidemiology Collaboration). A new equation to estimate glomerular filtration rate. Ann Intern Med 2009;150:604-12. https://doi.org/10.7326/0003-4819-150-9-200905050-00006

8. Ludlow M, Jesudason S, Johnson DW. Automatic reporting of estimated glomerular filtration rate in Australia turns 13: re-examining the impact. Med J Aust 2018;209:244-5. https://doi.org/10.5694/mja18.00544

9. Johnson DW, Jones GR, Mathew TH, Ludlow MJ, Doogue MP, Jose MD, et al:; Australasian Creatinine Consensus Working Group. Chronic kidney disease and automatic reporting of estimated glomerular filtration rate: new developments and revised recommendations. Med J Aust 2012;197:224-5. https://doi.org/10.5694/mja11.11329
10. Michels WM, Grootendorst DC, Verduijn M, Elliott EG Dekker FW, Krediet RT. Performance of the Cockcroft-Gault, MDRD, and new CKD-EPI formulas in relation to GFR, age, and body size. Clin J Am Soc Nephrol 2010;5:1003-9. https://doi.org/10.2215/CJN.06870909

11. Delanaye P, Guerber F, Scheen A, Ellam T, Bouquegneau A Guergour D, et al. Discrepancies between the CockcroftGault and Chronic Kidney Disease Epidemiology (CKD-EPI) equations: implications for refining drug dosage adjustment strategies. Clin Pharmacokinet 2017;56:193-205. https://doi.org/10.1007/s40262-016-0434-z

12. Dowling TC, Wang ES, Ferrucci L, Sorkin JD. Glomerular filtration rate equations overestimate creatinine clearance in older individuals enrolled in the Baltimore Longitudinal Study on Aging: impact on renal drug dosing. Pharmacotherapy 2013;33:912-21. https://doi.org/10.1002/ phar.1282

13. Björk J, Grubb A, Gudnason V, Indridason OS, Levey AS Palsson $\mathrm{R}$, et al. Comparison of glomerular filtration rate estimating equations derived from creatinine and cystatin $\mathrm{C}$ : validation in the Age, Gene/Environment SusceptibilityReykjavik elderly cohort. Nephrol Dial Transplant 2018;33:1380-8. https://doi.org/10.1093/ndt/gfx272

14. Chew-Harris JS, Chin PK, Florkowski CM, George P, Endre Z Removal of body surface area normalisation improves raw-measured glomerular filtration rate estimation by the Chronic Kidney Disease Epidemiology Collaboration equation and drug dosing in the obese. Intern Med J 2015;45:766-73. https://doi.org/10.1111/imj.12791

15. Bouquegneau A, Vidal-Petiot E, Moranne O, Mariat C, Boffa JJ, Vrtovsnik F, et al. Creatinine-based equations for the adjustment of drug dosage in an obese population. Br J Clin Pharmacol 2016;81:349-61. https://doi.org/10.1111/bcp.12817

16. Matzke GR, Aronoff GR, Atkinson AJ Jr, Bennett WM, Decker BS, Eckardt KU, et al. Drug dosing consideration in patients with acute and chronic kidney disease-a clinical update from Kidney Disease: Improving Global Outcomes (KDIGO). Kidney Int 2011;80:1122-37. https://doi.org/10.1038/ ki.2011.322 